Bol. Acad. peru. leng. 65. 2019 (169-189)

\title{
DE NUEVO SOBRE EL DIMINUTIVO EN LA BOLIVIA ANDINA DE LA PRIMERA MITAD DEL SIGLO XIX: UNA APROXIMACIÓN SOCIOLINGÜÍSTICA
}

\author{
José Luis Ramírez Luengo \\ Universidad Autónoma de Querétaro
}

Fecha de recepción: $\quad$ 03/03/2019

Fecha de aceptación: $\quad 31 / 05 / 2019$

No cabe duda de que, entre los diferentes fenómenos que individualizan al español andino, el empleo del diminutivo constituye uno de los más relevantes, y como tal lo señalan numerosos estudiosos que analizan desde antiguo estas variedades americanas de la lengua (Toscano Mateus, 1953: 422-4; Caravedo, 1996: 167-8; Lipski, 1996: 268; Granda, 2002: 50): a este respecto, son varias las cuestiones que se acostumbran a enumerar como caracterizadoras de estos usos diferenciales del diminutivo en la región, y entre ellas destacan algunas como su altísima frecuencia de uso en comparación con el que estos sufijos tienen en otras variedades, los diferentes valores semántico-pragmáticos que el diminutivo puede adquirir y muy especialmente su aplicación a bases que, en general, no admiten estos morfemas ${ }^{1}$,

1 Tal descripción, se ha de decir, no es solo aplicable al español andino, sino que resulta también apropiada para otras variedades del continente, como puede ser, entre otras, 
tales como el adverbio, el pronombre o los numerales y posesivos, con ejemplos como esito, biencito, allacito, lueguito (Mendoza Quiroga, 2008: 230) o cuatrito y suyito (NGLE, 2009: 634, 1398)2.

Por supuesto, la consideración de las hablas empleadas en la parte occidental de la actual Bolivia como parte de ese más general español andino determina que lo que se acaba de describir acerca del uso de los sufijos diminutivos para todos los Andes sea también aplicable a esta región, y así no sorprende descubrir que todos los autores que se ocupan de la descripción de esta variedad del español - a manera de ejemplo, Coello Vila (1996: 177), Mendoza Quiroga (2008: 229), Callisaya Apaza (2012: 74)—dedican unas palabras al empleo de estos sufijos en la zona y coinciden en indicar la existencia en ella de las tres características señaladas anteriormente, esto es, una alta frecuencia de uso, la adquisición de valores semántico-pragmáticos que van más allá de la expresión de tamaño o afecto y su aplicación a bases muy diferentes del sustantivo y del adjetivo ${ }^{3}$.

En cuanto a los orígenes de estos particulares usos del diminutivo, Reynoso Noverón (2001-2: 116) plantea la hipótesis de una "posible activación por contacto», es decir, que

la proliferación de diminutivos en el español de América y su uso en categorías poco usuales en otras variantes puede deberse a una reactivación, actualización y reajuste de los patrones polisémicos que han caracterizado al diminutivo desde el latín, debido al contacto lingüístico y cultural establecido en América a partir del descubrimiento.

la del altiplano central mexicano (Company, 2007: 112-114); no parece tan válida, sin embargo, para regiones como, por ejemplo, el Río de la Plata, que a día de hoy parece mostrar a este respecto un comportamiento mucho más cercano al del español peninsular que al de otras variedades americanas.

2 Esto demuestra lo acertado del aserto de Lázaro Mora (1999: 4650-1), quien recuerda que, pese a la estrecha relación que une al diminutivo con el sustantivo y el adjetivo, en realidad cualquier base léxica puede recibir sufijación apreciativa de este tipo.

3 Aunque quizá resulte innecesario, cabe indicar que la presencia del diminutivo con algunos adverbios (prontito) u otras categorías morfológicas como el gerundio (andandito) tampoco es desconocida en el español peninsular (Náñez, 2006: 26), si bien la frecuencia de estos usos — y las mismas posibilidades de empleo— son notablemente más reducidas que las que se dan en el español de América en general y en el andino de forma particular. 
Esta idea en cierto modo sustratística de que el contacto entendido de la forma más amplia posible — con las lenguas autóctonas americanas es el que produce ${ }^{4}$ la aparición de estos usos especiales del diminutivo es también aceptada, en el caso del español andino, por autores como Caravedo (1992: 295), Godenzzi (1996: 90), Granda (2002: 50) o el ya mencionado Mendoza Quiroga (2008: 229), para los cuales la situación actual es el resultado de la influencia que, sobre estas variedades del español, ha ejercido el quechua - y más en concreto, el sufijo - cha, «que, aparte de indicar tamaño pequeño, puede también denotar afección o desprecio» (Mendoza Quiroga, 2008: 229)—, así como, en el caso del occidente boliviano, el sufijo -lla del aimara, de significado análogo al de la ya referida partícula quechua (Mendoza Quiroga, 2008: 229).

Frente a la situación sincrónica, conocida ya con cierta precisión, resultan mucho menos estudiados los aspectos que tienen que ver con la diacronía del fenómeno, de manera que aún es necesario responder a cuestiones como la época en que se produce la intensificación en el uso del diminutivo o la ampliación de las bases a las que se aplica, así como las causas últimas de ambos procesos, es decir, si son el resultado del contacto lingüístico del español con las lenguas autóctonas o, por el contrario, si se trata de una evolución propiamente hispánica. A este respecto, conviene señalar que un trabajo muy reciente (Ramírez Luengo, 2016) sobre el empleo de estos sufijos en el habla de un bilingüe —en realidad, trilingüe- perteneciente a los estratos sociales populares de la sociedad boliviana de los primeros años del siglo xIx permite confirmar ya la existencia, en esta época, de una situación muy semejante a la que se describe para la sincronía actual, caracterizada — según se dijo yapor el empleo de -ito como sufijo productivo único, la clara preferencia por los empleos pragmáticos frente a los referenciales y la extensión de la derivación apreciativa a algunas de las bases que, más allá del adjetivo y del sustantivo, la aceptan hoy en esta variedad, como son los adverbios de lugar y de tiempo.

$4 \quad \mathrm{O}$ al menos favorece. 
Es posible, por tanto, responder ya a algunos de los interrogantes históricos que se han planteado en el párrafo anterior y que tienen que ver con la cronología de estos usos, pero sigue en pie la cuestión de su origen, habida cuenta de que su existencia en los albores de la Independencia en el habla de los bolivianos bilingües demuestra, naturalmente, que tales usos son utilizados en esta época por los hablantes que poseen este perfil sociolingüístico, pero en ningún caso evidencia que la causa que determina el fenómeno sea la secular convivencia del español con el quechua y el aimara; en este sentido, parece necesario - según se indicaba ya en Ramírez Luengo (2016: 124)— «estudiar los usos del diminutivo en hablantes bolivianos decimonónicos monolingües, para ver de este modo si el empleo de estos elementos es semejante en ambos grupos» o, por el contrario, si existen diferencias de peso que - ahora sí- se pueden atribuir de manera indudable al influjo de las lenguas autóctonas sobre el sistema morfosintáctico del español.

Con el propósito de confirmar que estos usos peculiares del diminutivo característicos del español andino tienen su génesis en el contacto entre el español y las lenguas indígenas, en el presente trabajo se propone llevar a cabo una comparación entre la situación que, a este respecto, se registra en dos hablantes del mismo origen geográfico y de la misma sincronía - el occidente andino de la actual Bolivia en la primera parte del siglo $\mathrm{XIX}^{5}$ - que se diferencian, sin embargo, por su nivel socioeducacional y por su conocimiento de las lenguas propias de la región; se pretende, por tanto, ofrecer un acercamiento de carácter

5 Aunque la importancia del siglo xix en la historia del español americano ya ha sido señalada en otras ocasiones (Ramírez Luengo, 2007: 28), cabe repetir aquí, siquiera de forma esquemática, algunos de los hechos y transformaciones que justifican la trascendencia que aquí se concede a este siglo, entre los que destacan sin duda la imposición de las nuevas capitales políticas como modelos normativos y, por tanto, la normativización de los usos propios regionales - desarrollados en momentos anteriores y divergentes de una zona a otra- o la hispanización lingüística de amplios grupos sociales del continente y, como consecuencia de ello, la aparición y/o extensión de nuevas situaciones de contacto, así como de nuevas variedades de español indigenizado (Ramírez Luengo, 2011: 15-17). La elección de este momento para el estudio que se está llevando a cabo, por tanto, trasciende el mero hecho - también importante, naturalmente- de contar con informantes adecuados para una aproximación como la que se quiere llevar a cabo en estas páginas, y se justifica, así, por el carácter fundamental que el Ochocientos tiene en la historia lingüística del Nuevo Mundo en general y de la región andina boliviana en particular. 
sociolingüístico en el que se atienda fundamentalmente a las variables del nivel social y del bilingüismo ${ }^{6}$, con el propósito de comprobar si ambos grupos coinciden en el uso del diminutivo.

Como no podía ser de otra forma, para llevar a cabo una aproximación como la inmediatamente enunciada, que incide en la variación de tipo diastrático, se ha tomado como objeto de estudio un informante de cada uno de los grupos sociales establecidos anteriormente —esto es, clase alta monolingüe frente a clase baja bilingüe—, que, más allá de esta diferencia, comparten la práctica totalidad de circunstancias vitales ${ }^{7}$ : así, si en el primer caso se ha analizado el epistolario que escribe María Guadalupe Cuenca de Moreno en 1811, en el segundo se ha optado por trabajar con el Diario de guerra que confecciona el militar José Santos Vargas; ambos autores coinciden en los factores diatópicos y cronológicos, al nacer en los Andes bolivianos durante la última década del siglo XIX, pero presentan una muy notable diferencia en cuanto a su nivel socioeducacional - relativamente alto en el caso de la criolla sucreña y bajo en el del militar de Oruro- y muy especialmente en el conocimiento de las lenguas autóctonas, que el soldado domina desde la infancia (Mendoza, 2008: XXVIII) y que, por otra parte, María Guadalupe Cuenca presumiblemente ignora ${ }^{8}$.

6 Variables, cabe decir, estrechamente relacionadas en el Alto Perú de las primeras décadas del siglo XIx, momento en el que la dicotomía clases altas monolingües vs. clases bajas bilingües probablemente representa a un porcentaje muy mayoritario de la población hispanohablante de la región (Ramírez Luengo, 2015: 114).

7 Se diferencian, sin embargo, en una característica fundamental como es su lugar de residencia, habida cuenta de que, mientras que el informante del nivel socioeducacional bajo desarrolla su vida en el ámbito geográfico donde nace, la representante de los grupos cultos monolingües se desplaza a la ciudad de Buenos Aires (Ramírez Luengo, 2010: 162); con todo, la pertinencia de ambos informantes para un estudio como el que se pretende llevar a cabo en estas líneas está avalada por los positivos resultados que se han obtenido de su comparación — también con una perspectiva en cierto modo sociolingüística- en un estudio previo sobre la configuración fónica del español boliviano de este mismo momento (Ramírez Luengo, 2015).

8 Para un perfil más detallado de ambos informantes, María Guadalupe Cuenca y José Santos Vargas, desde un punto diatópico/diastrático — en línea, pues, con los postulados de la dialectología histórica一, véanse respectivamente Ramírez Luengo (2010: 162) y Ramírez Luengo y Velázquez Patiño (2014: 35-36). 
Más allá de lo ya señalado respecto de los informantes, se hace necesario así mismo, describir los textos que componen el corpus de estudio, y a este respecto es importante indicar que, si bien se muestran tipológicamente discordantes - en un caso se trata de un conjunto de cartas familiares y en el otro, de un diario personal-, lo cierto es que existen también ciertos factores que permiten asemejarlos en cuanto al registro que utilizan: en efecto, circunstancias como el grado de confianza que existe entre la patricia sucreña y su marido o el carácter de mano inbábil (Marquilhas, 2000: 234-241) del militar determinan que en ambos casos el investigador se enfrente a una escritura muy cercana al polo de la inmediatez comunicativa (Oesterreicher, 2004: 732-734), lo corpus y permite, por tanto, llevar a cabo una comparación válida del empleo del diminutivo que se refleja en ellos?.

De este modo, teniendo en cuenta todo lo dicho hasta el momento —así como la aplicación de una metodología semejante en el análisis del diminutivo ${ }^{10}$ - , parece posible llevar a cabo a partir de estos textos una aproximación de tipo sociolingüístico al empleo de los sufijos apreciativos que se descubre en los grupos alto/monolingüe y bajo/bilingüe de la Bolivia occidental del Ochocientos, en el convencimiento de que la descripción de sus semejanzas y muy especialmente de sus diferencias ha

9 Es necesario señalar que para el estudio de estos elementos no se ha acudido a los originales de ambos subcorpus, sino a ediciones de los mismos que — conviene decir- resultan totalmente fiables: en el caso de Vargas, se ha partido de la lectura del Diario que ofrecen los paleógrafos del Archivo y Biblioteca Nacional de Bolivia (ABNB) en Vargas (2008); en el de María Guadalupe Cuenca, el hecho de que Álzaga (1967) ofrezca, junto a la transcripción, los facsímiles de las cartas ha permitido comprobar todos los diminutivos del corpus en las reproducciones fotográficas. Por supuesto, todos los ejemplos citados a lo largo del presente estudio se toman de estas dos obras: en el caso de Vargas, se ofrece al lector la página de la edición señalada, mientras que, en el de Cuenca de Moreno, se anota el número de la carta en la que aparece la ocurrencia concreta que se quiere destacar.

10 Esta metodología común aplicada a ambos corpus afecta tanto a los aspectos que se van a analizar - en concreto, 1) el diminutivo que se emplea, 2) el predominio de significados referenciales o pragmáticos y 3) las bases a las que se añade- como a los criterios que se van a emplear para la determinación de los aspectos ya señalados: por ejemplo, la apelación al significado en la discriminación entre diminutivos lexicalizados y no lexicalizados (cartilla 'cuaderno pequeño e impreso' vs. cartita 'carta pequeña'), o el empleo de pruebas de carácter semántico (sustitución del diminutivo por pequeño + base y comprobación del posible cambio de significado: casita $=$ 'pequeña casa'; pobrecito $\neq$ 'pequeño pobre') para la valoración de estos elementos como referenciales o pragmáticos. 
de aportar datos de primera importancia para el mejor entendimiento de los orígenes y el desarrollo histórico de los fenómenos que, en relación con estos elementos, caracterizan hoy al español andino.

De este modo, la búsqueda sistemática de los diminutivos que en los dos subcorpus se emplean con tal función - esto es, que no aparecen en voces «opacas, no transparentes o lexicalizadas» (NGLE, 2009: 635) ${ }^{11}$ — ha dado como resultado 145 ejemplos en el caso del texto del informante bilingüe de nivel socioeducacional bajo y 27 en el epistolario de la criolla monolingüe, lo que en principio se podría interpretar como una frecuencia de empleo más alta en el primero de ellos y, por tanto, como un argumento a favor de la hipótesis de que la influencia de las lenguas autóctonas favorece un uso especialmente abundante de estos elementos (Coello Vila, 1996: 177; Mendoza Quiroga, 2008: 229); sin embargo, lo cierto es que la disparidad en la extensión de los materiales comparados — notablemente más extenso en el caso del Diario del guerrillero orureño- dificulta en mucho, si no impide totalmente, hacer comparaciones en cuanto a la frecuencia de utilización de estos elementos, que deberá llevarse a cabo en el futuro con corpus semejantes no solo desde el punto de vista cuantitativo, sino también desde otras perspectivas como la tipológica ${ }^{12}$.

Frente a las dificultades de interpretación inmediatamente expuestas, es de destacar una coincidencia morfológica indudable que se registra en ambos subcorpus, la presencia de un único sufijo diminutivo - en concreto, la forma -ito— con tal función: en efecto,

11 Tal y como se indicaba en Ramírez Luengo (2016: 115), hay que tener en cuenta que las nociones de transparencia y opacidad no son absolutas, sino más bien graduales, «puesto que se basan en la conciencia lingüística del hablante, siempre variable, a menudo dependiente de su cultura particular y, por tanto, difícil de objetivar» (NGLE, 2009: 635-6); en este caso concreto -y como estrategia de aplicación común a ambos corpus-, se ha considerado diminutivo lexicalizado aquel que forma unidades léxicas presentes en el DLE (1992) y cuya definición no se explica como resultado del proceso de disminución de la base (a manera de ejemplo, guerrilla o la ya señalada cartilla).

12 De hecho, esta disparidad en lo tipológico impide también establecer comparaciones respecto de la frecuencia de uso de estos elementos con otros trabajos que abordan su empleo diacrónico en diferentes áreas del mundo hispánico (Fontanella de Weinberg, 1987: 110; Ramírez Luengo, 2005). 
tanto en los escritos de Vargas como en los de María Guadalupe Cuenca, este elemento resulta el único morfema productivo, con ejemplos como quebradita (148) y pueblito (p. 230), en el primer caso, o lugarsito (carta 4) e hijitas (carta 10), en el segundo ${ }^{13}$. A este respecto, cabe decir que, si bien no puede sorprender que los textos constaten el proceso de decantación de los diferentes sufijos apreciativos a favor de un único elemento — proceso que, como se indica en Ramírez Luengo (2007: 70-1), se produce en la práctica totalidad de la América hispana a lo largo del siglo XviII-, quizá sí sea interesante señalar que este proceso resulta general y común a los dos sociolectos del español boliviano decimonónico que se están estudiando y no posee, por tanto, ninguna distribución de tipo sociolingüístico en esta región ${ }^{14}$; se puede constatar, así, que, por lo que se refiere a esta cuestión, el siglo XIX refleja ya la imposición del estado de cosas que a día de hoy se descubre en la zona (Coello Vila, 1996: 177) y se muestra en este punto decididamente contemporáneo.

En contraste con esta coincidencia entre los dos subcorpus en relación con la preferencia clara por el sufijo -ito, resulta interesante analizar los valores semánticos que el diminutivo adopta en el habla de Vargas y Cuenca de Moreno, pues es aquí donde se registran diferencias de peso que pueden comenzar a aportar luz acerca de la cuestión básica que se quiere dilucidar en estas páginas, a saber, si los usos propiamente andinos del diminutivo guardan relación con

13 Naturalmente, ambos subcorpus muestran ejemplos formales del sufijo -illo, pero en todos los casos en elementos lexicalizados, tales como hablillas y pandilla (pp. 18 y 109), en el caso de Vargas, y Delgadillo, en el de Cuenca de Moreno (carta 4); tales ejemplos no modifican, pues, la descripción del empleo de estos elementos establecida en Ramírez Luengo (2016: 117), en la que se señala que «en la primera mitad del siglo xix existe solo un diminutivo que funge como tal en el español boliviano occidental, -ito, y que se acompaña de determinadas voces en las que - como testigos o remanentes de una situación de variación morfológica previa- pervive un sufijo -illo lexicalizado», descripción a la que ahora se puede añadir, además, su carácter común a los diferentes diastratos que componen la variedad analizada.

14 Tal situación contrasta, por ejemplo, con la que se descubre en el Uruguay de esta misma época, donde el empleo del diminutivo sí parece ofrecer cierto valor sociolingüístico, habida cuenta de que, mientras que en los estratos populares -ito es prácticamente exclusivo $(97.46 \%)$, en los niveles socioeducacionales altos su empleo se reduce a un 64.28\% y compite con otros sufijos como -illo o -uelo (Ramírez Luengo, 2006: 43-44). 
el conocimiento - $y$, por tanto, con la influencia- de las grandes lenguas regionales.

A este respecto, es preciso señalar en primer lugar que, de acuerdo con Company (2007: 109), en español «el diminutivo es una forma altamente polisémica que puede expresar tanto un valor referencial: la disminución del tamaño de la base, cuanto significados pragmáticos valorativos de distinta índole», entre los que se pueden destacar «la proximidad afectiva, la ironía, el respeto, la humildad, el desprecio o la conmiseración»; por supuesto, tal polisemia y convivencia de significados referenciales y pragmáticos resulta general en todas las variedades de la lengua, pero — tal y como demuestra con datos porcentuales el trabajo de la profesora mexicana (Company, 2007: 112-113) — mientras que algunas de ellas como la castellana/ centropeninsular se muestran equilibradas en cuanto al empleo de los dos valores, otras como la mexicana - y también la andina boliviana, en palabras de Mendoza Quiroga (2008: 229) — utilizan estos elementos, primordialmente, "para significar diversas valoraciones de tipo pragmático que el hablante proyecta sobre esas entidades en una determinada situación comunicativa» (Company, 2007: 112).

Pues bien, la aplicación de estos criterios semánticos a los diversos diminutivos que aparecen en los dos subcorpus representativos de los hablantes monolingües y bilingües del español andino decimonónico demuestra la existencia de diferencias porcentuales de cierta importancia entre ellos en relación con la preferencia por el empleo de las posibles significaciones — referenciales $v$ s. pragmáticas - que el sufijo diminutivo puede acarrear, tal y como pone de manifiesto la tabla $1^{15}$ :

15 Es necesario señalar que a veces no resulta sencillo determinar el significado que predomina en algunos ejemplos, pues «el solapamiento que en ocasiones se produce entre ambas significaciones determina la existencia de unos casos fronterizos» (Ramírez Luengo, 2016: 119) de valor ambiguo; para solucionar esta cuestión, se ha atendido a las pruebas semánticas ya señaladas en la nota 10 , así como a otras cuestiones quizá más discutibles: a manera de ejemplo, los múltiples casos de Marianito que aparecen en las cartas de María Guadalupe (cartas 1, 2, 3, 4, 5, 6 y 10) se han considerado primordialmente referenciales por cuanto sirven para distinguir al niño del padre de nombre semejante, si bien es evidente la proximidad afectiva que también denotan. 


\begin{tabular}{|c|c|c|}
\hline VALORES & BILINGÜES (J. S. Vargas) & MONOLINGÜES (M. G. Cuenca) \\
\hline Referenciales & $61(42,06 \%)$ & $17(62,96 \%)$ \\
\hline Pragmáticos & $84(57,93 \%)$ & $10(37,03 \%)$ \\
\hline TOTAL & $145(100 \%)$ & $27(100 \%)$ \\
\hline
\end{tabular}

Tabla 1. Distribución semántica de los diminutivos en el corpus

Salta a la vista, por tanto, que - como no podía ser de otra formaambos significados conviven en los dos subcorpus que se están analizando en estas líneas, pero también resulta evidente la distancia que, respecto a esta cuestión, se descubre entre los dos grupos sociales considerados: en efecto, mientras que en María Guadalupe Cuenca los valores referenciales son claramente mayoritarios (ejemplos 1 y 2), en el caso del hablante bilingüe son los pragmáticos los que predominan (ejemplos 3 y 4), con una diferencia en los porcentajes sin ninguna duda relevante, de algo más de 20 puntos $^{16}$.

1. Se lo dije al inglés, y escrivió ese papelito y me dijo que lo pusiera dentro de mi carta (carta 8)

2. No te escrivo más largo por que no hay más tiempo que vn ratito (carta 9)

3. Entonces picó su caballo (...) y asércase más a la tropa preguntando el quién vive, los otros no contestan más que la Patria, se asercaban agachaditos por entro de los matorrales (p. 116).

16 De hecho, a las diferencias de tipo cuantitativo inmediatamente señaladas es posible sumar otras de carácter cualitativo que resultan de no escaso interés para la obtención de una imagen más clara de las discrepancias en el uso del diminutivo que muestran los informantes: en efecto, más allá del porcentaje claramente minoritario de usos pragmáticos en el epistolario de María Guadalupe Cuenca, hay que decir que estos aparecen en todas las ocasiones con nombres propios como Mariquita, Anita o Panchita (cartas 3, 4, 7, 9 , $10,11)$; en el caso de José Santos Vargas, sin embargo, no se descubre tal restricción al aparecer valores no referenciales en elementos tan variados como nombres propios (Tomasito, p. 335) y comunes (indiecito, p. 319), así como adjetivos (agachaditos, p. 116) y otras categorías —adverbios: prontito (p. 358), arribita (p. 392) — de las que se habla a continuación. 
4. El desgraciado Ayllón a las 10 del día le da una puñalada a una muger llamada Manuela Navarro (alias la Gordita) en la pierna (p. 371).

A la luz de estos datos, por tanto, se puede llegar ya a dos conclusiones de cierto interés: por un lado, que el empleo predominante de valores pragmáticos o referenciales en el momento analizado parece estar determinado por factores de tipo social y/o más probablemente-por el conocimiento de las lenguas indígenas regionales; por otro, que mientras que María Guadalupe se muestra en este punto más alejada del uso del diminutivo que Mendoza Quiroga (2008: 229) describe como general para la sincronía actual en el occidente boliviano ${ }^{17}$, el militar orureño, sin embargo, presenta ya una situación muy semejante a la que constituye ese uso, de manera que parece posible mantener la hipótesis de que van a ser las clases bajas —y lo que es más importante: bilingües - las que primero van a presentar un estado de cosas que, general hoy en la zona, caracteriza de forma muy marcada al español andino boliviano contemporáneo.

Como consecuencia de esta disparidad fundamental en cuanto a la aparición de los diversos valores semánticos que el diminutivo lleva aparejados, es posible señalar otra cuestión que establece aún mayores diferencias en lo que respecta al empleo de estos sufijos en los diversos estratos sociolingüísticos que conforman el español boliviano andino de los inicios de la etapa republicana: en efecto, los datos extraídos de las cartas de la criolla sucreña parecen evidenciar que los niveles socioeducacionales altos restringen el empleo de estos sufijos a las bases léxicas que los permiten en la norma general —es decir, el sustantivo (ejemplo 5) y el adjetivo (ejemplo 6)—; el Diario de Vargas, por el contrario, no solo los añade a tales categorías morfológicas (ejemplos 7 y 8 ), sino que en un porcentaje relativamente amplio, de casi un $25 \%$, presenta estos elementos también en otras categorías en las que quizá no son diatópicamente tan frecuentes, tales como el cuantificador todo

17 Se acerca más a la situación que, de acuerdo con Company (2007: 212), muestra a este respecto, por ejemplo, la variedad castellana/centropeninsular de hoy. 
(ejemplo 9), el adjetivo adverbializado claro (ejemplo 10) o diferentes adverbios (ejemplos 11-13):

5. Te escrivo ese de 1 y otra esquelita que por no perder ocación te escriví la noche del 4 (carta 4)

6. Nuestro hijo sigue en la escuela, siempre flaquito (carta 1)

7. En la abrita de Corocoro yendo a Lequepalca, donde también los mataron a dos mositos que havían sido cobradores de alcabala (p. 236)

8. Mi maestro don José Jacinto Quevedo se fue con toda su familia a la yglesia de San Francisco con todas sus criadas y criados, y a mí me dejó [solito] echandome llave ala puertaycalle (p. 14)

9. Ya no abansaron, se reunieron toditos, descansaron un buen rato, se dirijieron para Quillacollo (p. 207)

10. Todas las voces de los oficiales del enemigo y exortaciones se oíya y aun los cintarasos con que contenían a los soldados, clarito (p. 186)

11. Le da el tiro al comandante Fajardo cerquita a quemarropa (p. 267)

12. Al capitán Moreno Lira lo destinó a retaguardia sosteniendo la carga al enemigo con quinse hombres de caballería, lueguito se bajaron estos y Moreno por últimas (p. 156)

13. Hiciera con vos un atentado, pero no, porque sois un imfeliz soldado, y os encargo el amor a la Patria (...), que haorita en este momento desapareserá mi existencia después de padeser tantos años (p. 410)

Se descubre de nuevo, por tanto, una diferencia en el uso de estos elementos que parece estar determinada por la distinta adscripción sociolingüística de los dos informantes analizados y que concuerda, además, con la otra conclusión apuntada anteriormente al hablar de las preferencias por los usos pragmáticos o referenciales: que es el representante de los grupos populares el que exhibe una situación más cercana a la norma actual del español andino boliviano (Mendoza Quiroga, 2008: 229), no solo en lo que tiene que ver con la asignación porcentualmente mayoritaria de valores pragmáticos al sufijo diminutivo, 
sino también, como se acaba de ver, en lo que se refiere a la ampliación del empleo de este elemento morfológico a bases léxicas — cuantificadores, adverbios, etc. - en las que su aparición resulta mucho más restringida desde el punto de vista geográfico ${ }^{18}$.

De este modo, la comparación del uso del diminutivo que los informantes analizados muestran en sus corpus ofrece ya una serie de conclusiones de cierto interés para la mejor y más completa descripción de esta cuestión en el español de la Bolivia occidental en los albores del siglo XIx, así como datos de cierta relevancia para la valoración de la (posible) influencia de las lenguas autóctonas, quechua y aimara, en la imposición de los empleos peculiares de estos elementos que caracterizan hoy la variedad empleada en la zona.

Es necesario indicar, en primer lugar, que, desde un punto de vista estrictamente morfológico, ambos autores coinciden en mostrar una preferencia absoluta por el elemento -ito, que a la luz de estos datos resulta ser el único sufijo apreciativo productivo en la zona y en el momento dados, independientemente del estrato socioeducacional o del nivel de bilingüismo que presenten los informantes. Por supuesto, tal situación no resulta del todo sorprendente, puesto que no constituye sino el reflejo regional de los procesos de decantación del diminutivo que experimenta el español de América a lo largo de los siglos Xvil y muy especialmente XVIII (Fontanella de Weinberg, 1992: 95-96; Ramírez Luengo, 2007: 7071), los cuales determinan el triunfo de un único morfema derivativo generalmente, aunque no siempre, -ito — en esta función; más destacable resulta, sin embargo, la total coincidencia que se descubre en ambos subcorpus, por cuanto, en algunas variedades americanas de esta misma

18 Con todo, es necesario señalar que, tal y como se indicaba en Ramírez Luengo (2016: 122), la situación que ofrece el texto de Vargas no resulta exactamente igual a la que hoy se descubre en la zona, pues no se registra ni un solo ejemplo de sufijo apreciativo con elementos como pronombres, numerales, posesivos o deícticos, frecuentes hoy en la región (NGLE, 2009: 634, 1398); queda, pues, para estudios posteriores dilucidar «si tal ausencia se debe a que todavía no se dan en el español de la época casos como suyito, abicito y dositas - lo que implicaría una generalización posterior del diminutivo a bases como estas- o a que, aun dándose en la oralidad (...), no hacen su aparición en el texto por motivaciones difíciles de precisar» (Ramírez Luengo, 2016: 122). 
época, la elección de una u otra forma de diminutivo - es decir, el empleo absoluto de -ito frente a su convivencia con -illo o con -uelo- sí parece estar determinada por criterios sociolingüísticos y, más en concreto, por el nivel sociocultural de los hablantes (Ramírez Luengo, 2006: 43-44).

Ahora bien, frente a esta coincidencia (de interés relativo) resultan mucho más relevantes las diferencias que se pueden registrar en el empleo de estos elementos, que en principio se pueden atribuir a la pertenencia de José Santos Vargas y María Guadalupe Cuenca a distintos estratos de la sociedad boliviana decimonónica y, como consecuencia de lo anterior, a su distinto conocimiento de las lenguas indígenas andinas: a este respecto, cabe señalar en primer lugar que, mientras que la criolla sucreña utiliza el diminutivo preferentemente con valores de tipo referencial (62.96\%), José Santos Vargas muestra una situación totalmente opuesta y una clara preferencia por los usos pragmáticos (57.93\%), con diferencias marcadas entre ambos — de más de 20 puntos porcentuales - en el empleo de sendos significados; a estas diferencias cuantitativas se suman, además, otras de carácter cualitativo, pues los valores pragmáticos en María Guadalupe parecen estar restringidos a los diminutivos que se añaden a nombres propios (Mariquita, Panchita); sin embargo, en el caso del guerrillero orureño se descubren no solo en sustantivos propios y comunes (Tomasito, gordita), sino también en otras categorías léxicas, tales como cuantificadores (toditos) o adverbios (lueguito, ahorita).

En línea con esta última idea, conviene indicar que también se registran diferencias de gran interés en lo que respecta a las bases léxicas a las que se añade el sufijo apreciativo: así, mientras que en el caso de la informante de los niveles altos/monolingües estos elementos aparecen exclusivamente en sustantivos y adjetivos, en el representante de los niveles bajos/bilingües se descubre una mayor flexibilidad al respecto que conlleva, como se señaló en el párrafo anterior, su aplicación - en un porcentaje no desdeñable, de casi el $25 \%$ del total- a otros elementos como, por ejemplo, cuantificadores, adjetivos adverbializados o diferentes adverbios de muy distinta significación. A partir de aquí, por tanto, es posible llegar a dos conclusiones de notable importancia para la más correcta descripción de la historia de estos elementos en 
el español andino: por un lado, que en el siglo xix su empleo no es semejante en todos los estratos de la sociedad boliviana occidental, sino que se descubren diferencias notables entre los diversos informantes que parecen estar determinadas por el nivel socioeducacional y/o el conocimiento de las lenguas propias de la región; por otro, que son los estratos populares bilingües los que presentan una situación semejante a la que actualmente se describe de esta zona (Coello Vila, 1996: 177; Mendoza Quiroga, 2008: 229; Callisaya Apaza, 2012: 74), mientras que en los niveles elevados y monolingües se descubre un estado de cosas más próximo al registrado en otras variedades del español y, por tanto, más alejado de las características que, respecto a esta cuestión, se consideran típicamente andinas.

Pues bien, es precisamente esta última constatación la que resulta de especial trascendencia para responder la cuestión que se planteaba al comienzo de estas páginas, a saber, si los usos que caracterizan al español de la región tienen su origen en el contacto de esta lengua con el quechua y el aimara: si se tiene en cuenta que tales usos aparecen en el siglo xIx de forma exclusiva en algunos hablantes de esta variedad, que tales hablantes se caracterizan precisamente por su conocimiento de estas lenguas y que, en el caso de los monolingües, se registra una ausencia total de tales fenómenos, parece posible sostener que, efectivamente, la influencia de las lenguas andinas va a ser un factor determinante en la imposición de estos empleos peculiares del diminutivo, que se pueden considerar, por tanto, como una clara consecuencia del contacto lingüístico, tal cual sostienen, entre otros autores, Caravedo (1992: 295), Godenzzi (1996: 90), Granda (2002: 50) o Mendoza Quiroga (2008: 229).

Por otro lado, este análisis parece favorecer, además, desde la morfosintaxis la hipótesis — sostenida anteriormente desde el punto de vista fónico (Ramírez Luengo y Velázquez Patiño, 2014: 34-35)— de la complejidad sociolingüística que caracteriza al español andino boliviano del siglo XIX, en el que conviven al menos dos variedades lingüísticas claramente diferenciadas: «aquella propia de las clases criollas privilegiadas, sin prácticamente influencia —-más allá del léxico— de las lenguas de 
adstrato» y «la que caracteriza a los grupos populares bilingües y en menor medida monolingües, que se va a ver caracterizada, precisamente, por el marcado influjo de las lenguas autóctonas regionales» (Ramírez Luengo y Velázquez Patiño, 2014: 35). A este respecto, si se tiene en cuenta que a día de hoy los empleos propiamente andinos del diminutivo no se reducen al habla de los bilingües, sino que resultan también habituales en monolingües en español (Mendoza Quiroga, 2008: 229), los datos de este estudio parecen sugerir una ampliación de tales empleos desde una de las variedades lingüísticas referidas —el denominado español indigenizado - a la propia de los estratos altos/monolingües, lo que demuestra que «tales variedades no van a permanecer aisladas la una de la otra», sino que, en realidad, «se van a influir y confundir a lo largo de toda la centuria, en un complicado juego que determinará la variación sociolingüística que hoy en día se encuentra en las zonas ya mencionadas» (Ramírez Luengo, 2011: 17).

En definitiva, si en Ramírez Luengo (2016: 124) se indicaba que «la situación que ofrece el diminutivo en la Bolivia andina de la primera mitad del siglo xix (...) resulta muy semejante a la que se ha descrito para la sincronía actual de la región», lo cierto es que esta nueva aproximación al tema obliga a modificar en parte esta afirmación, al descubrirse una situación bastante más compleja que parece estar determinada por criterios de tipo sociolingüístico y que aporta, además, importantes argumentos a favor de la idea de que es el contacto lingüístico españollenguas indígenas el factor que produce la génesis ${ }^{19}$ de las peculiaridades que, en lo que respecta al uso del diminutivo, caracteriza hoy a las variedades andinas del español.

Súmese a esto, por último, una doble constatación que trasciende el análisis puntual que se está realizando en este trabajo: por un lado - y como se ha dicho ya anteriormente- que, si bien en los albores

19 Por supuesto, queda por responder la cuestión de si este contacto lingüístico constituye la causa única que explica estos usos o, por el contrario, se trata de un factor coadyuvante que se añade a otros propiamente intrasistemáticos, según la visión de la causación múltiple defendida —y aplicada brillantemente a diferentes fenómenos del español americanopor Granda (1991, 1997). 
del Ochocientos ya se había producido la imposición de los usos andinos del diminutivo en determinados hablantes, será muy probablemente durante esta centuria cuando se generalice por todos los estratos de la sociedad, lo que una vez más refuerza la idea de la importancia del siglo de las independencias en la configuración histórica del español americano (Ramírez Luengo, 2011: 15); por otro, y desde un punto de vista metodológico, «que la inclusión del factor sociolingüístico en los estudios de dialectología histórica supone un aporte fundamental a la hora de ofrecer una visión más ajustada de la situación del español en algún periodo del pasado» (Ramírez Luengo, 2015: 121), lo cual había quedado ya demostrado en el trabajo inmediatamente citado para el nivel fónico, pero que estas páginas confirman — como no podía ser menos — también para cuestiones de tipo morfosintáctico al ofrecer un acercamiento más profundo, y por esto mismo más realista, a lo que constituye la historia de uno de los rasgos más característicos de la variedad de español que se utiliza actualmente en el occidente de Bolivia. 
https://doi.org/10.46744/bapl.201901.009

\section{BIBLIOGRAFÍA}

ÁLZAGA, E. (1967). Cartas que nunca llegaron. María Guadalupe Cuenca y la muerte de Mariano Moreno. Buenos Aires: Emecé Editores.

CALLISAYA APAZA, G. (2012). El español de Bolivia. Contribución a la dialectología y a la lexicografía hispanoamericana. Salamanca: Universidad de Salamanca. http://gredos.usal.es/jspui/ bitstream/10366/121133/1/DTI_CallisayaApazaGregorio_Tesis.pdf. Martes, 7 de mayo de 2019, 16:45 horas.

CARAVEDO, R. (1992). El atlas lingüístico hispanoamericano en el Perú, observaciones preliminares, en Lingï̈́stica Española Actual, 14, 287-299.

. (1996). Perú. En Manual de dialectología hispánica. El español de América. Manuel Alvar (dir.), Barcelona: Ariel, 152-168.

COELlO VILA, C. (1996). Bolivia. En Manual de dialectología hispánica. El español de América. Manuel Alvar (dir.), Barcelona: Ariel, 169-183.

COMPANY, C. (2007). El siglo XVIII y la identidad lingüística de México. México DF: UNAM / Academia Mexicana de la Lengua.

FONTANELLA DE WEINBERG, M. (1987). El español bonaerense. Cuatro siglos de evolución lingüística (1580-1980). Buenos Aires: Hachette.

. (1992). El español de América. Madrid: MAPFRE.

GODENZZI, J. (1996). Transferencias lingüísticas entre el quechua y el español, en Signo y Seña, 6, 73-99.

GRANDA, G. de. (1991). De nuevo sobre la causación múltiple en el español de América (a propósito de dos rasgos 
https://doi.org/10.46744/bapl.201901.009

morfosintácticos del español paraguayo). En Scripta Philologica, in honorem Juan M. Lope Blanch, II. Elisabeth Luna Traill (coord.), México DF: Universidad Nacional Autónoma de México, 491-506.

. (1997). Replanteamiento de un tema controvertido, génesis y retención del doble posesivo en el español andino, en Revista de Filología Española, 77 (1-2), 139-147.

. (2002). El noroestre argentino, área lingüística andina. En Lingüística en contacto. Español y quechua en el área andina suramericana. Germán de Granda, Valladolid: Universidad de Valladolid, 39-62.

LÁZARO MORA, F. (1999). La derivación apreciativa. En Gramática descriptiva de la lengua española, III. Ignacio Bosque y Violeta Demonte (coords.), Madrid: Espasa-Calpe, 4645-4682.

LIPSKI, J. (1996). El español de América. Madrid: Cátedra.

MARQUILHAS, R. (2000). A Faculdade las Letras. Leitura e escrita em Portugal do século XVII. Lisboa: Imprensa Nacional-Casa da Moeda.

MENDOZA, G. (2008). Introducción. En Diario de un combatiente de la Guerra de Independencia (1814-1825). José Santos Vargas, La Paz: ABNB/Fundación Cultural BCB/ Plural Editores, XXIII-LXV.

MENDOZA QUIROGA, J. (2008). Bolivia. En El español en América. Contactos lingüisticos en Hispanoamérica. Azucena Palacios (coord.), Barcelona: Ariel, 213-236.

NÁÑEZ FERNÁNDEZ, E. (2006). El diminutivo. Historia y funciones en el Español Clásico y Moderno. Madrid: Universidad Autónoma de Madrid. 
https://doi.org/10.46744/bapl.201901.009

OESTERREICHER, W. (2004). Textos entre inmediatez y distancia comunicativas. El problema de lo hablado escrito en el Siglo de Oro. En Historia de la Lengua Española. Rafael Cano Aguilar (coord.), Barcelona: Ariel, 729-769.

RAMÍREZ LUENGO, J. (2005). Variación gramatical y tipos textuales, el diminutivo en la época de Don Quijote. En Ámbitos, 13, 29-34.

. (2006). Una nota de sociolingüística histórica, el diminutivo en el español uruguayo del siglo XIX, en Res Diachronicae, 5, 39-45.

. (2007). Breve historia del español de América. Madrid: Arco Libros.

. (2010). El español del occidente de Bolivia en la época de las Independencias, notas fonético-fonológicas, en Boletín de Filología de la Universidad de Chile, 45(1), 159-174.

. (2011). La lengua que hablaban los próceres. El español de América en la época de las Independencias. Buenos Aires: Voces del Sur.

- (2015). La configuración fónica del español de la Bolivia andina en la primera mitad del siglo XIX, notas sociolingüísticas, en Études Romanes de Brno, 36(2), 111-123.

. (2016). El diminutivo en la Bolivia andina de la primera mitad del siglo XIX, valores y funciones, en Cuadernos de Investigación Filológica, 42, 111-127.

RAMÍREZ LUENGO, J. y VELÁZQUEZ PATIÑO, E. (2014). El español de los bilingües altoperuanos en la primera mitad del siglo XIX. Rasgos fónicos. En La historia del español 
https://doi.org/10.46744/bapl.201901.009

boy. Estudios y perspectivas. José Luis Ramírez Luengo y Eva Patricia Velásquez Upegui (coords.), Lugo: Axac, 33-54.

REAL ACADEMIA ESPAÑOLA. (1992). Diccionario de la lengua española ( $21^{\text {a }}$ ed.). Madrid: Espasa-Calpe.

REAL ACADEMIA ESPAÑOLA / ASOCIACIÓN DE ACADEMIAS DE LA LENGUA ESPAÑOLA. (2009). Nueva gramática de la lengua española. Madrid: Espasa-Calpe.

REYNOSO NOVERÓN, J. (2001-2). Desarrollos paralelos en el contacto español-lenguas indígenas, indigenismos léxicos y diminutivos, en Anuario de Lingüística Hispánica, 17-18, 111-128.

TOSCANO MATEUS, H. (1953). El español del Ecuador. Madrid: Consejo Superior de Investigaciones Científicas.

VARGAS, J. (2008). Diario de un combatiente de la Guerra de la Independencia. 1814-1825. La Paz: ABNB/Fundación Cultural BCB/ Plural Editores. 